\title{
OPTIMIZATION OF EARLY DIAGNOSIS OF NECROTIC ENTEROCOLITIS IN NEWBORNS
}

Received 15 August 2020;

Received in revised form 12 September 2020: Accepted 15 September 2020

\section{Davud Magomedmirzaev ${ }^{凶}(\mathbb{0})$, Aleksei Zhidovinov (ㅇ, Pavel Permyakov}

\author{
Department of Pediatric Surgery, Astrakhan State Medical University, \\ Astrakhan, Russia
}

\section{davudmagomedmirzaev@yandex.ru}

timely and rational prescription of antibiotics, but also is determined by a complex of diagnostic and therapeutic measures aimed at early detection of signs of complicated course of NEC $[1,6,8]$

It is known that in patients with NEC any parts of the gastrointestinal tract (GIT) can be damaged. The prevailing pathological process in more than $90 \%$ of cases is inflammation and coagulation necrosis of the intestinal wall. The proven risk factors in the pathogenesis of NEC are prematurity, early onset of feeding, asphyxia, intestinal ischemia, immune disorders, infection, and low gestational age $[1,5,9,4,6]$.

to optimize early diagnosis and treatment of necrotic enterocolitis in newborns using laboratory and instrumental diagnostic methods.

\section{MATERIALS AND METHODS}

Our study encompassed 30 newborns, 10 days old, with necrotic enterocolitis (acute and subacute forms). There were 18 boys (60\%) and 12 girls (40\%) in the group. All newborns underwent $x$-ray examination of the abdominal cavity, ultrasound of the abdominal organs. The laboratory tests included: complete blood count $(\mathrm{CBC})$ every 6 hours, clinical urinalysis (UA), coagulogram (thrombin time, activated partial thromboplastin time (APTT), fibrinogen), biochemical blood analysis (C-reactive protein (CRP), glucose, total protein, albumins, triglycerides, bilirubin, creatinine, urea), tests of procalcitonin in the blood on the basis of immunochemiluminescence; bacteriological blood testing for sterility (isolation of pure culture), antimicrobial susceptibility testing of isolated cultures, fecal occult blood test.

The objective of the suggested diagnostic techniques was to identify diagnostic criteria for necrotic enterocolitis (NEC). It is very challenging for pediatric surgeons to reliably assess, whether medical management is possible or surgical intervention is required. This challenge justifies a priority of optimizing diagnosis and treatment of NEC.

\section{RESULTS AND DISCUSSION}

To assess the severity of the condition and the stage of the disease, we used the criteria of Bell's 
stage. During the first stage, there was a stretching of intestinal loops on the abdominal $\mathrm{x}$-ray survey, CBC: anemia, leukocytosis $+25.4 \times 10^{9} /$, leukopenia, $+4.5 \times 10^{9} / \mathrm{l}$, a shift of the leukocyte formula to the left, UA without changes, a biochemical blood test within normal parameters, a fecal analysis for hidden bloodpositive. Ultrasound of the abdominal cavity showed the absence of infiltrates and other formations in the abdominal cavity, sluggish intestinal peristalsis. During the second stage, on an overview $x$-ray of the abdominal cavity, dilation of intestinal loops, an increase in the thickness of the intestinal wall due to edema and inflammation, in the $\mathrm{CBC}$ thrombocytopenia is lower than $+150 \times 10^{\circ} / 1$, UA is unchanged, Biochemical blood test: hypoalbuminemia, hyperbilirubinemia, C-reactive protein $+10 \mathrm{mg} / \mathrm{l}$, increased urea. Ultrasound of the abdominal cavity: reduced peristalsis in the affected segments, uneven, moderate dilatation of intestinal loops. Fecal calprotectin was observed in the range of $1.1-1.4 \mathrm{mg} / \mathrm{g}$. During the third stage, subserous pneumatosis of the intestinal wall with its thickening, fixed intestinal loops, gas in the portal vein system, and pronounced ascites were showed on the x-ray. Ultrasound of the abdominal cavity: pronounced local thickening of the intestinal wall, infiltrates are located, between the loops of the intestine and in the pelvic cavity, CBC neutropenia $+1.5 \times 10^{9} / \mathrm{l}$. Serum electrolytes: hyponatremia, hypocalcemia, hypokalemia. Coagulogram: increase in APTT, thrombin time. Biochemical blood analysis: hypoalbuminemia, hyperbilirubinemia, C-reactive protein $>10 \mathrm{mg} / \mathrm{l}$, increased urea, residual nitrogen, increasing procalcitonin $+2 \mathrm{ng} / \mathrm{ml}$ is a marker of sepsis; ABS of blood $\mathrm{pH}+7.2$. The development of intestinal necrosis is indicated by the preservation of metabolic acidosis for more than 4 hours against the background of intensive therapy. In $21(70 \%)$ children a bacteriological blood test gave a positive result. $11(36.6 \%)$ children were operated on. The indicator of fecal calprotectin varied from $1.5-2.5 \mathrm{mg} / \mathrm{g}$. This provides evidence of a deep lesion of the intestinal wall and reflects the severity of the intestinal perforation and enables to select management strategies for newborns.

\section{ONCLUSION}

1. Early diagnosis of ulcerative-necrotic enterocolitis in newborns is aimed at determining the level of fecal calprotectin in the stool.

2. If the level of fecal calprotectin is higher than 1.1 $\mathrm{mg} / \mathrm{g}$, necrotic enterocolitis is diagnosed (patent RU 2705379 C1).

3. If the level of fecal calprotectin is higher than 1.5 $\mathrm{mg} / \mathrm{g}$, surgery is considered to be a better option.
Therefore, we have confirmed the feasibility of using fecal calprotectin for early diagnosis of NEC.

\section{REFERENCES}

1. Alekhina, L. A. Necrotizing enterocolitis in extremely premature children: issues and possible solutions. / L.A. Alekhina// Bulletin of the Federal center for heart, blood and endocrinology them. V.A. Almazov. - 2010. - No. 6. - P. 2.

2. Ivanova, O. G. The effect of hemodynamically significant arterial duct on the development of necrotizing enterocolitis in preterm neonates with extremely low body mass at birth. /O. G. Ivanova, S. V. Jonushene, V. E. Osherov// Siberian medical journal. - 2011. - Vol. 105, No. 6. - P. 262-264.

3. Karpova, I. YU., Experience of surgical treatment of newborns with necrotizing enterocolitis. / I. Yu. Karpova, V. V. Parshikov, G. B. Batanov // Herald of surgery. I.I.Grekova. - 2012. - No. 2.- P. 58-60.

4. Magomedmirzaev D. Sh., Zhidovinov A. A., Permyakov P. E., Misrikhanov M. K., Petruk N. V., Vakhabova H., Shavarikova B., Balayeva Z., Aliev E. Diagnosis and treatment of necrotizing enterocolitis in newborns. Literature review.//Archive Euromedica. - 2019. - No. 2. - P. 94-96 https://doi. org/10.35630/2199-885X/2019/9/2/94,

5. Podkamenev, A. V. Pathogenesis and treatment of ulcerative necrotizing enterocolitis and perforations of the gastrointestinal tract in neonates /A. V. Podkamenev//Abstract of dissertation on competition of a scientific degree of candidate of medical Sciences. Irkutsk 2008. - 42 p.

6. Protopopova, N.V. Risk factors for ulcerative necrotizing enterocolitis in newborns./N.V. Protopopova, V.V. Podkamenev, A.V. Podkamenev// Diagnostic issues in pediatrics. - 2010. - No. 1.- P. 43-48.

7. Razin M. P., Minaev S. V., Turabov I. A., Strelkov N. S., Zhidovinov A. A. Children's surgery. / M.P. Razin, S.V. Minaev, I.A. Turabov, N.S. Strelkov, A.A. Zhidovinov// Textbook: $2^{\text {nd }}$ ed. Moscow: GEOTAR-Media. - 2020. pp. 158-167.

8. ShCHERbinin, R. L., Vecherkin, V. A., RezVAN, S. G., KRYUCHKov, YU. V. Results of complex treatment of necrotizing enterocolitis in newborns. / R. L. Shcherbinin, V. A. Vecherkin, S. G. Rezvan, Yu. V. Kryukov// Pediatric surgery. - 2012. - No. 1. - P. $12-15$.

9. Ng, P.C., Chan, K.Y., Poon, T.C. Biomarkers for prediction and diagnosis of necrotizing enterocolitis. Clin. Perinatol. 2013; 40 (1): 149-159 PMID: 23415270 DOI: 10.1016/j.clp.2012.12.005

10. Diagnosis and Management of Necrotizing Enterocolitis: An International Survey of Neonatologists and Pediatric Surgeons. Valpacos M., Arni D., Keir A.c Aspirot A, Wilde J. , Beasley S. , De Luca D. , Pfister R., Karam O. Neonatology 2017, 113(2):170-176 PMID: 29241163 DOI: $10.1159 / 000484197$ 